\title{
CD200-CD200R dysfunction exacerbates microglial activation and dopaminergic neurodegeneration in a rat model of Parkinson's disease
}

Shi Zhang ${ }^{1+}$, Xi-Jin Wang $^{1+}$, Li-Peng Tian ${ }^{1}$, Jing Pan ${ }^{1}$, Guo-Qiang Lu' ${ }^{1}$, Ying-Jie Zhang ${ }^{2}$, Jian-Qing Ding ${ }^{1,2^{*}}$ and Sheng-Di Chen ${ }^{1,2^{*}}$

\begin{abstract}
Background: Increasing evidence suggests that microglial activation may participate in the aetiology and pathogenesis of Parkinson's disease (PD). CD200-CD200R signalling has been shown to be critical for restraining microglial activation. We have previously shown that expression of CD200R in monocyte-derived macrophages, induced by various stimuli, is impaired in PD patients, implying an intrinsic abnormality of CD200-CD200R signalling in PD brain. Thus, further in vivo evidence is needed to elucidate the role of malfunction of CD200CD200R signalling in the pathogenesis of PD.
\end{abstract}

Methods: 6-hydroxydopamine (6-OHDA)-lesioned rats were used as an animal model of PD. CD200R-blocking antibody (BAb) was injected into striatum to block the engagement of CD200 and CD200R. The animals were divided into three groups, which were treated with 6-OHDANeh (PBS), 6-OHDA/CAb (isotype control antibody) or 6-OHDA/BAb, respectively. Rotational tests and immunohistochemistry were employed to evaluate motor deficits and dopaminergic neurodegeneration in animals from each group. HPLC analysis was used to measure monoamine levels in striatum. Morphological analysis and quantification of CD11b- (or MHC II-) immunoreactive cells were performed to investigate microglial activation and possible neuroinflammation in the substantia nigra (SN). Finally, ELISA was employed to assay protein levels of proinflammatory cytokines.

Results: Compared with 6-OHDA/CAb or 6-OHDANeh groups, rats treated with 6-OHDA/BAb showed a significant increase in counts of contralateral rotation and a significant decrease in TH-immunoreactive (TH-ir) neurons in SN. A marked decrease in monoamine levels was also detected in 6-OHDA/BAb-treated rats, in comparison to 6-OHDA/ Veh-treated ones. Furthermore, remarkably increased activation of microglia as well as up-regulation of proinflammatory cytokines was found concomitant with dopaminergic neurodegeneration in 6-OHDA/BAb-treated rats.

Conclusions: This study shows that deficits in the CD200-CD200R system exacerbate microglial activation and dopaminergic neurodegeneration in a 6-OHDA-induced rat model of PD. Our results suggest that dysfunction of CD200-CD200R signalling may be involved in the aetiopathogenesis of PD.

\footnotetext{
*Correspondence: jqding18@yahoo.com; chen_sd@medmail.com.cn

† Contributed equally

'Department of Neurology \& Institute of Neurology, Ruijin Hospital, Shanghai

Jiao Tong University School of Medicine, 197 Ruijin Er Road, Shanghai

200025, P. R. China

Full list of author information is available at the end of the article
} 


\section{Background}

Parkinson's disease (PD) is the second most common neurodegenerative disease in the world, and is characterized by dopaminergic neuron loss in the substantia nigra pars compacta (SNpc) [1]. PD was first described by James Parkinson in 1817, and the aetiology of PD still remains unknown. However, emerging investigations suggest that multiple factors, both genetic and acquired, contribute to the loss of dopaminergic cells in the substantia nigra (SN) of these patients [2-4]. Among these culprits, accumulated evidence suggests that neuroinflammation, which is characterised by activation of microglia and subsequent production of proinflammatory cytokines, may play an important role in the neurodegenerative process in PD. Activated microglia are found in the SN of mesencephalon in the brain of PD patients [5-8] and of parkinsonian animal models [9-13]. Molecules related to neuroinflammation, such as tumor necrosis factor-alpha (TNF- $\alpha$ ), IL-6, IL- $1 \beta$, interferongamma (IFN- $\gamma$ ), and superoxide, have been found colocalized with microglia in brain, and in cerebrospinal fluid and serum of PD patients as well [6,7,14-22]. Taken together, those previous studies suggest that persistent activation of microglia is dynamically involved in the disease's progression.

CD200R, an important inhibitory receptor present on microglia [23], actively maintains microglia in a quiescent state through its interaction with CD200, a transmembrane glycoprotein expressed on neurons [24-29]. Recent publications have demonstrated that disruption of CD200-CD200R engagement can cause abnormal activation of microglia and consequent pathological changes. Microglia in CD200-deficient $\left(\mathrm{CD} 200^{-/-}\right)$mice exhibit more characteristics of activation [30]. They are aggregated, less ramified and have shorter glial processes, as well as a disordered arrangement and increased expression of CD11b and CD45. Moreover, this increased microglial response is substantiated by enhanced expression of Class II major histocompatibility complex (MHC II), TNF- $\alpha$ and inducible nitric oxide synthetase (iNOS) [31]. Thus, CD200 $0^{-/-}$mice display earlier onset of experimental autoimmune encephalomyelitis (EAE) [30]. In addition, preventing CD200CD200R interactions with CD200R-blocking antibodies also induces augmented microglial activation in EAE rats $[32,33]$. Conversely, $\mathrm{CD} 200^{-1-}$ mice receiving exogenous CD200R agonist, including CD200 antigen [34] or an agonist anti-CD200R antibody [35], are resistant to the induction of experimental autoimmune uveoretinitis (EAU). All of these findings suggest that decreased interaction between CD200 and CD200R is related to increased activation of microglia. Interestingly, decreased expression of CD200 and CD200R have also been found in hippocampus and inferior temporal gyrus of patients suffering from Alzheimer's disease [36]. Down-regulation of CD200 has also been detected in brain of multiple sclerosis (MS) patients [37]. These results suggest that a deficient CD200-CD200R system may be involved in the progression of various neurological disorders $[38,39]$. Our previous study revealed altered regulation of CD200R in monocyte-derived macrophages from PD patients [40]. We also found that blocking CD200-CD200R engagement dramatically exacerbates dopaminergic neurodegeneration in a primary neuron/ microglia co-culture system [41]. Thus, further in vivo evidence is needed to thoroughly elucidate the role of malfunction of CD200-CD200R signalling in the pathogenesis of PD. In the present study, we used a CD200R blocking antibody to destroy CD200-CD200R engagement in hemiparkinsonian rats, induced by 6-OHDA injection. We found that the impairment of CD200CD200R interaction resulted in increased microglial activation and corresponding neurodegeneration in this animal model of PD.

\section{Methods}

\section{Materials}

Specific monoclonal antibodies against CD200R (CD200R-blocking antibody, BAb), CD11b, MHC II and isotype control mouse IgG1 (Control antibody, $\mathrm{CAb}$ ) were obtained from Serotec (Indianapolis, IN, USA). The ELISA kit for rat-TNF $\alpha$ was obtained from R\&D Systems (Minneapolis, MN, USA). The ELISA kit for rat-IL-6 was purchased from BD (San Diego, CA, USA). Elite $A B C$ kit and 3,3'-diaminobenzidine tetrahydrochloride (DAB) substrate were purchased from Vector (Vector Laboratories, Burlingame, CA, USA). The BCA Protein Assay Kit was from Thermo Fisher Scientific (Rockford, IL, USA). High-performance liquid chromatography (HPLC)-grade methanol was obtained from BDH Laboratory (Poole, UK). All other chemicals were obtained from Sigma-Aldrich (St. Louis, MO, USA).

\section{Animals}

All animal experiments were performed according to the NIH Guide for the Care and Use of Laboratory Animals and were approved by the Shanghai Jiao Tong University School of Medicine Animal Care and Use Committee (2009087). Male Sprague-Dawley rats (10-12 weeks old, weighing 220-260 g at the start of the experiment) were provided by the Shanghai Institutes of Biological Sciences animal house, and were caged in groups of 5 with food and water given ad libitum. The animals were kept in a temperature-controlled environment at $22 \pm 2^{\circ}$ $\mathrm{C}$ on a 12:12 light-dark cycle. 


\section{Steoreotaxic surgery}

For stereotaxic surgery, rats were anesthetized with an intraperitoneal injection of pentobarbital $(50 \mathrm{mg} / \mathrm{kg})$. When the animals were deeply anesthetized, they were placed in a stereotactic apparatus. Subsequently, the rats were injected with BAb $(1 \mu \mathrm{g} / \mu \mathrm{l}, 5 \mathrm{ul}$ for each site) or CAb $(1 \mu \mathrm{g} / \mu \mathrm{l}, 5 \mathrm{ul}$ for each site) into the right striatum (anterior lesion site: AP: $1.0 \mathrm{~mm}$ anterior to the bregma, L: $2.6 \mathrm{~mm}$ from the midline, $\mathrm{D}: 4.5 \mathrm{~mm}$ from the dura; posterior lesion site: AP: $0.3 \mathrm{~mm}$ posterior to the bregma, L: $3.5 \mathrm{~mm}$ from the midline, D: $4.5 \mathrm{~mm}$ from the dura). The sham groups were injected with vehicle (10 mM PBS, $5 \mu \mathrm{l}$ for each site, Veh). The next day, each group was injected with 6-OHDA $(4 \mu \mathrm{g} / \mu \mathrm{l}$ in $0.9 \%$ saline with $0.02 \%$ ascorbic acid, $2 \mu \mathrm{l}$ for each site) into the right ascending medial forebrain bundle (MFB) (one $4.2 \mathrm{~mm}$ posterior to bregma, $1.2 \mathrm{~mm}$ lateral to the midline, and $7.8 \mathrm{~mm}$ below the dura, and another $4.4 \mathrm{~mm}$ posterior to bregma, $1.7 \mathrm{~mm}$ lateral to the midline, and $7.8 \mathrm{~mm}$ below the dura). The microinjection coordinates used were obtained from a rat brain atlas by Paxinos and Watson. The injection was made at a rate of $1 \mu \mathrm{l} /$ min using a $10 \mu \mathrm{l}$ Hamilton syringe with a 26-gauge needle. At the end of each injection, the syringe needle was left in place for $5 \mathrm{~min}$, and then was slowly withdrawn to prevent reflux of the solution.

\section{Tissue preparation}

At 21 days post 6-OHDA-injection, animals were deeply anesthetized with pentobarbital $(100 \mathrm{mg} / \mathrm{kg}$, i.p.) and perfused through the aorta with $150 \mathrm{ml}$ of $0.9 \%$ saline, followed by $250 \mathrm{ml}$ of a cold fixative consisting 4\% paraformaldehyde in $100 \mathrm{mM}$ phosphate buffer (PB). Brains were then dissected out (3-4 $\mathrm{mm}$ in thickness) and postfixed for 24 hours with paraformaldehyde in $100 \mathrm{mM}$ PB before placed into $30 \%$ sucrose solution in phosphate-buffered saline for 24-72 hours at $4^{\circ} \mathrm{C}$. Brains were then cryosectioned coronally on a Leica1650 cryostat (cut thickness: $25 \mu \mathrm{m}$ ) with a random start, and including sections before and after both anatomical regions to confirm the entire structure was quantified. Sections were collected serially throughout the SN and placed into PBS for further experiments.

\section{Immunohistochemistry}

Free-floating sections were pretreated with $0.3 \% \mathrm{H}_{2} \mathrm{O}_{2}$ in 0.1 M PBS (pH 7.2-7.5) for $10 \mathrm{~min}$ at RT (60 rpm) to block endogenous peroxidase activity, then washed with $0.1 \mathrm{M}$ PBS for 3 times. The tissue was then blocked with diluted blocking serum (Elite ABC kit, Vector Laboratories, Burlingame, CA, USA) for 20 minutes at room temperature. Sections were then incubated with the primary antibody to TH (mouse anti- TH, 1:4000, Sigma), CD11b (mouse anti-CD11b, 1:1000, serotec) or
MHC II (mouse anti-MHC II, 1:1000, serotec) overnight at $4{ }^{\circ} \mathrm{C}$. The following day the sections were washed and then incubated with diluted biotinylated secondary antibody (Vector laboratories) for $30 \mathrm{~min}$ at room temperature. The secondary antibody was amplified using avidin-biotin complex (Vector laboratories) for $30 \mathrm{~min}$ at room temperature. Finally the sections were developed with 3,3'-diaminobenzidine tetrahydrochloride (Vector Laboratories). Sections were then mounted onto glass slides and dried overnight. The next day the slides were passed through a gradient of ethyl alcohol and xylene to dehydrate the tissue. The slides were then coverslipped using permount mounting medium.

\section{Cell quantification}

Unbiased stereological estimates of DA (TH-positive cell) neuron numbers were performed using StereoInvestigator analysis software (MicroBrightField, Williston, VT), combined with a Nikon Eclipse E600 microscope, and the optical fractionator method according to previously published reports $[42,43]$. Boundaries in the SN were defined according to previously defined anatomical analysis in the rat [44] and cells were counted from every sixth $25-\mu \mathrm{m}$ section $(\sim 24$ sections $)$ along the entire SN (to ensure coefficient of errors $<0.1$, the rostral-caudal length of the $\mathrm{SN}$ was $4 \mathrm{~mm}$ ), by investigators blinded to treatment history, with a $60 \times$ objective. In brief, optical dissectors (area of counting frame, 64,000 $\mathrm{mm}^{3}$; guard height, $2 \mu \mathrm{m}$; spaced $300 \mu \mathrm{m}$ apart in the $\mathrm{x}$-direction, and $200 \mu \mathrm{m}$ apart in the $\mathrm{y}$-direction) were applied to each section in the series throughout the entire SN (including pars reticulata and compacta; estimates are reflective of two sides; $\mathrm{n}=5$ for each group). We show the percent of neurons remaining on the ipsilateral side compared to those on the intact contralateral side. Values are expressed as the mean \pm S.E.M. of all animals in each group.

Microglial quantification similarly used adjacent (8 sections) serial sections. An observer blind to sample identity counted numbers of CD11b-immunoreactive (CD11b-ir) positive cells in the SN on each side (Nikon microscope at a $40 \times$ magnification). Here the $\mathrm{X}-\mathrm{Y}$ step length used was between $300-400 \mathrm{~mm}$ in order to count 100-200 CD11b-ir cells in each side of the SN. A positive cell was defined as a nucleus covered and surrounded by CD11b immunostaining. The stage of cells was identified by their morphology. For quantitation of MHC II immunoreactive (MHC II-ir) cells, cells in stage 4 were identified by their morphology on MHC II staining under $40 \times$ magnification and counted in every sixth $25-\mu \mathrm{m}$-thick serial section of the $\mathrm{SN}$ of each rat using a two-blinded procedure. Graphs show the number of MHC II-ir cells in the SN. 
Measurements of dopamine and its metabolites by HPLC Animals ( $\mathrm{n}=5$ each of the following groups: 6-OHDA/ Veh, 6-OHDA/CAb, and 6-OHDA/BAb) were sacrificed by $\mathrm{CO}_{2}$ and their brains were quickly removed and placed on ice. The left and right striatum were freshly dissected out, weighed, frozen in liquid nitrogen, and stored at $-80^{\circ} \mathrm{C}$ for later use.

Each sample was homogenized by sonication in icecold $0.1 \mathrm{~mol} / \mathrm{L}$ perchloric acid and then centrifuged at $12,000 \mathrm{rpm}$ for 30 minutes at $4^{\circ} \mathrm{C}$. The supernatants $(20$ $\mu \mathrm{l})$ were injected into a high-performance liquid chromatography (HPLC) system coupled to an electrochemical detection device (Coularray; ESA, Chelmsford, MA) for measuring dopamine (DA), 3,4-dihydroxyphenylacetic acid (DOPAC) and homovanillic acid (HVA). The protein contents were determined in pellet fractions by the method described by Lowry [45], and expressed as $\mathrm{ng} / \mathrm{g}$ wet weight of tissue (ng/g WW)

\section{Classification of microglial activation}

We adapted a classification system for microglial activation according to Kreutzberg [46]:

Stage 1: Resting microglia. Rod-shaped soma with fine and ramified processes.

Stage 2: Activated ramified microglia. Elongated cell body with long and thicker processes.

Stage 3: Amoeboid microglia. Round body with short, thick and stout processes.

Stage 4: Phagocytic cells. Round cells with vacuolated cytoplasm; no processes can be observed at the light microscopy level.

Stages of microglia activation were confirmed by observation by at least two blinded observers. Black circles in Figure 2 show examples of microglia in different stages. All of these cell types are CD11b-ir, and MHC II stained only activated microglia but not resting microglia.

\section{Rotational behaviour}

Apomorphine-induced rotational behaviour was assessed at 7 and 21 days after 6-OHDA-injection. Rotational behaviour was tested in rotometer bowls [47]. Five minutes after intraperitoneal administration of apomorphine $(0.5 \mathrm{mg} / \mathrm{kg}$ diluted in $0.9 \%$ saline $)$, the total number of full $360^{\circ}$ rotations in the contralateral direction was counted for $30 \mathrm{~min}$.

\section{ELISA for TNF- $\alpha$ and IL-6}

Rats were killed by $\mathrm{CO}_{2}$ overdose followed by cervical dislocation and decapitation at 21 days after injection of 6-OHDA. The brain was removed and immediately transferred to ice and cut at the level of the infundibular stem forming a hindbrain block containing the SN. The SN were dissected, snap-frozen in liquid nitrogen and stored at $-80^{\circ} \mathrm{C}$. Tissue was homogenized on ice in $400 \mu \mathrm{l}$ of Tris- $\mathrm{HCl}$ buffer $(\mathrm{pH}=7.3)$ containing protease inhibitors $(10 \mathrm{mg} / \mathrm{ml}$ aprotinin, $5 \mathrm{mg} / \mathrm{ml}$ peptastin, $5 \mathrm{mg} / \mathrm{ml}$ leupeptin, $1 \mathrm{mM}$ PMSF). Homogenates were centrifuged at $10,000 \mathrm{~g}$ at $4^{\circ} \mathrm{C}$ for $10 \mathrm{~min}$ and then ultracentrifuged at 40,000 r.p.m. for 2 h. Supernatants were aliquoted and stored at $-80^{\circ} \mathrm{C}$ until use. BCA protein assays were performed to determine total protein concentration in each sample. Commercially available rat TNF- $\alpha$ (R\&D, Minneapolis, MN, USA and rat IL-6 kits (BD, San Diego, CA, USA) with high sensitivity were used to quantify these cytokines according to the manufacturers' instructions $(7.8 \mathrm{pg} / \mathrm{ml}$ for rTNF $-\alpha$ and $20 \mathrm{pg} / \mathrm{ml}$ for rIL-6). Three animals per group were analyzed and each sample was analyzed in duplicate.

\section{Statistical analysis}

Statistical analysis of the data was performed using GraphPad Prism version 5.00 for Windows (GraphPad Software, San Diego California, USA, http://www.graphpad.com). The results are reported as mean \pm SEM. Two-way ANOVA followed by Bonferroni's test was applied to determine significant differences among data of rotational experiments with two time points. Univariate one-way ANOVA and Tukey-Kramer post-hoc test were used to analyze data from other experiments between treated groups. The criterion for statistical significance was $\mathrm{P}<0.05$.

\section{Results}

$\mathrm{BAb}$ administration enhances rotational asymmetry in 6OHDA-induced hemiparkinsonian rats

Unilateral injection of 6-OHDA into medial forebrain bundle (MFB) induces the loss of dopaminergic cell in the ipsilateral SNpc and was used as a hemiparkinsonian animal model in this study. To investigate the role of CD200-CD200R dysfunction in 6-OHDAinduced neurotoxicity, we employed a CD200R monoclonal antibody to block CD200-CD200R engagement, which was first used by Wright, G. J. [32], and later by many other investigators [33,41,48-51]. In the present study, BAb, CAb or Veh was injected into striatum one day before 6-OHDA injection. Then, apomorphine-induced rotational behaviour was analyzed to assess unilateral degeneration of presynaptic dopaminergic neuron terminals at 7 and 21 days after 6OHDA injection. Although rats that had been microinjected with 6-OHDA/Veh could contralaterally rotate to the site of 6-OHDA lesion with apomorphine administration $(1.5 \pm 0.6$ at 7 days, $3.7 \pm 1.3$ at 21 days), apomorphine-induced rotation was significantly increased in 6-OHDA/BAb rats at both time points $(7.7 \pm 2.6$ and $18.3 \pm 2.3$ respectively, $\mathrm{p}<0.0001)$ 
(Figure 1). Pretreatment with BAb not only exacerbated but also accelerated (as early as 7 days) motor deficits in hemiparkinsonian rats (Figure 1). Animals that responded to apomorphine treatment with at least 7.0 turns/min could be regarded as successfully induced hemiparkinsonian rats $[43,52]$. The rats that received 6-OHDA/Veh treatment showed only $1.5 \pm 0.6$ turns/min at 7 days and $3.7 \pm 1.3$ turns/min at 21 days induced by apomorphine administration, and both of these values are less than 7.0 turns $/ \mathrm{min}$. So the dose of 6-OHDA $(16 \mu \mathrm{g})$ used in this experiment could be considered as a sub-toxic dose. However, rats treated with 6-OHDA/CAb did not show a significant increase in contralateral rotational number, $2.7 \pm 1.1$ turns $/ \mathrm{min}$ at 7 days and $4.7 \pm 1.7$ turns/min at 21 days, compared to the rats treated with 6-OHDA/Veh (Figure 1).

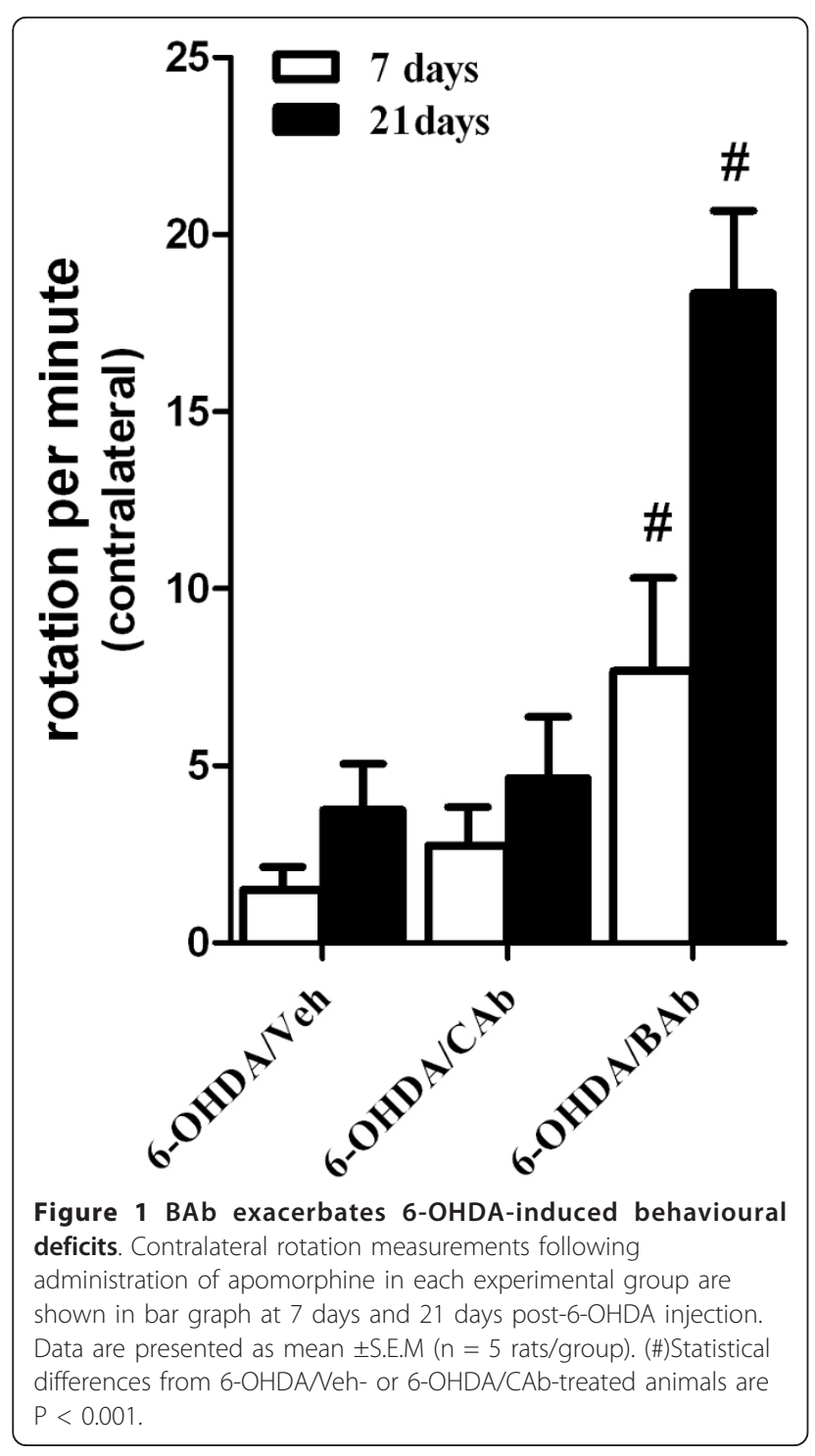

BAb administration exacerbates 6-OHDA-induced neurodegeneration

To confirm that the phenotype of our PD rats is consistent with dopaminergic neuron loss in $\mathrm{SN}$, we stained midbrain coronal sections with an antibody against tyrosine hydroxylase $(\mathrm{TH})$ and performed non-biased stereological estimation of $\mathrm{TH}$-immunoreactive ( $\mathrm{TH}$-ir) neurons in SN. We observed that a sub-toxic dose of 6-OHDA was able to induce moderate but not overt dopaminergic neurodegeneration in $\mathrm{SN}(55.0 \pm 6.0 \%$ of contralateral) (Figure 2A). Intrastriatal injection of BAb resulted in a significant decrease in $\mathrm{TH}$-ir neurons in whole $\mathrm{SN}$ in animals treated with 6-OHDA/BAb $(5.2$ $\pm 2.0 \%, \mathrm{P}<0.0001)$. However, no dramatic decrease in $\mathrm{TH}$-ir cells was observed between groups treated with 6-OHDA/Veh and 6-OHDA/CAb (Figure 2A). These results indicate an exacerbating effect of $\mathrm{BAb}$ on the degeneration of dopaminergic neurons. At higher magnifications, we observed that treatment of 6-OHDA/BAb not only decreased the number of $\mathrm{TH}$-ir cells but also their arborisation or fibers. TH-ir fibers (Figure 2 arrowheads) were less densely spread amongst TH-ir cell bodies (Figure 2 arrows) in the $\mathrm{SN}$ in 6-OHDA/BAbtreated rats (Figure 2G), compared to either control group (6-OHDA/Veh, 6-OHDA/CAb) (Figure 2E-F). There were no marked morphological differences in numbers of $\mathrm{TH}$-ir cells in $\mathrm{SN}$ between rats pretreated with CAb (6-OHDA/CAb) and Veh (6-OHDA/Veh) (Figure 2E-F). Furthermore, BAb administration had a significant effect on DA and its metabolites in ipsilateral striatum. Twenty-one days after 6-OHDA injection, the DA content of right striatum in 6-OHDA/Veh-treated rats was $1765 \pm 236 \mathrm{ng} / \mathrm{g}$ wet weight of tissue $(\mathrm{ng} / \mathrm{g}$ WW) $(\mathrm{n}=5)$ (Table 1). Protein levels of DA metabolites in this group were $894 \pm 95 \mathrm{ng} / \mathrm{g}$ WW $(\mathrm{n}=5)$ and 599 $\pm 104 \mathrm{ng} / \mathrm{g}$ WW $(\mathrm{n}=5)$ for DOPAC and HVA respectively (Table 1). Injection of CAb prior to 6-OHDAlesion did not cause significant changes in DA or its metabolites in the right striatum of rats in comparison to vehicle control animals (Table 1), while the contents of DA and its metabolites in 6-OHDA/BAb group were significantly lower than that in the 6-OHDA/Veh group. These values were $38 \pm 8 \mathrm{ng} / \mathrm{g}$ WW $(\mathrm{n}=5), 24 \pm 3 \mathrm{ng} / \mathrm{g}$ $\mathrm{WW}(\mathrm{n}=5)$ and $17 \pm 2 \mathrm{ng} / \mathrm{g} \mathrm{WW}(\mathrm{n}=5)$, respectively (Table 1).

\section{BAb treatment exacerbates 6-OHDA-induced microglial activation}

The direct effect of BAb is destruction of the balance between CD200 and its receptor. CD200R receptor is expressed only on microglia $[24,53,54]$.

Signal transferred from CD200 to its only known receptor, CD200R, has been shown to be critical for restraining microglial activation [30]. Thus, we studied 


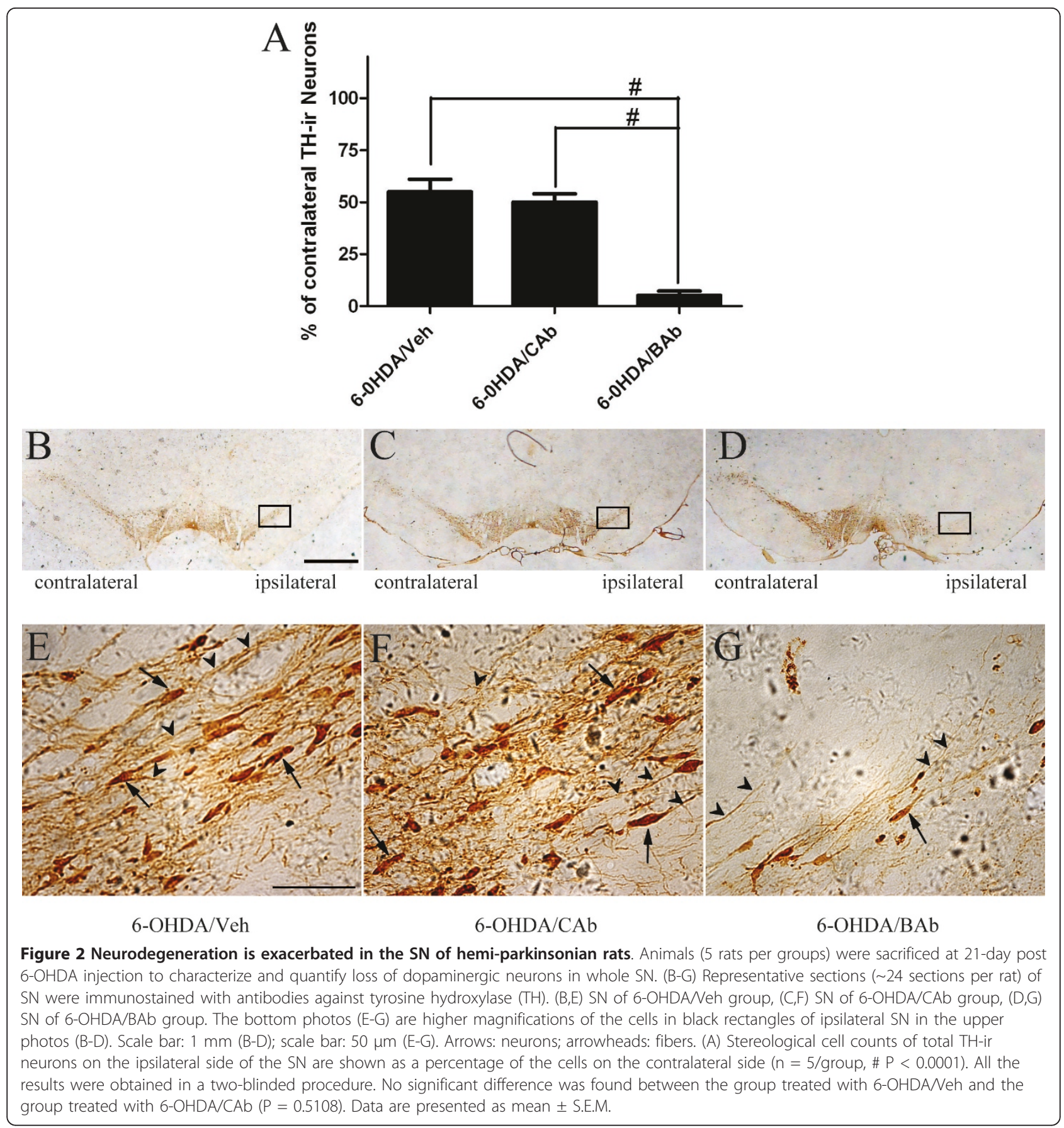

microglial activation and possible neuroinflammation in $\mathrm{SN}$ at 21 days post-6-OHDA-injection by immunohistochemistry as described in Methods.

First, we studied morphological changes and quantification of microglia using the microglia-specific marker CD11b (a constitutive marker of microglia). CD11b recognizes complement receptor type 3 (CR3), the expression of which is greatly increased in hyperactive microglia compared with resting microglia. In our study, profound microglial responses were observed in ipsilateral $\mathrm{SN}$ in rats following treatment with 6-OHDA/BAb (Figure 3F,I). Round and amoeboid cells (Stage 4) became predominant in the core of the $\mathrm{SN}$ and were mingled with rod-shaped (stage 3 ) or highly ramified (stage 2) microglia near the boundary (Figure 3I). Twenty one days post-6-OHDA injection there was an increase in CD11b-ir cells in all groups. In addition, we found that the total number of CD11b-ir cells in SN 
Table 1 BAb administration increases 6-OHDA-induced dopamine deficiency in ipsilateral striatum.

\begin{tabular}{cccc}
\hline Groups & \multicolumn{3}{c}{ Content (ng/g Wet weight of tissue) } \\
\cline { 2 - 4 } & DA & DOPAC & HVA \\
\hline 6-OHDANeh & $1765.0 \pm 235.6$ & $894.1 \pm 94.7$ & $598.8 \pm 103.6$ \\
\hline 6-OHDA/CAb & $1674.0 \pm 174.9$ & $836.7 \pm 72.3$ & $16.7 \pm 121.5$ \\
\hline 6-OHDA/BAb & $37.6 \pm 7.8{ }^{* * *}$ & $24.2 \pm 3 .{ }^{* * *}$ & \\
\hline${ }^{* *} \mathrm{p}<0.01,{ }^{* * *} \mathrm{p}<0.001$ compared to the 6-OHDANeh and 6-OHDA/CAb groups $(\mathrm{n}=5$ per group)
\end{tabular}

Results are expressed as mean \pm S.E.M. (ng/g WW) of total protein. Data are shown only for ipsilateral (right) side of striatum. Statistical analysis was performed by two-way ANOVA. ${ }^{* *} \mathrm{p}<0.01,{ }^{* * *} \mathrm{p}<0.001$ as compared to 6-OHDA/Veh lesion group.

was significantly increased in 6-OHDA/BAb-treated rats (716 $\pm 23 \%, \mathrm{P}=0.0002)$ versus 6 -OHDA/CAb-treated rats $(318 \pm 20 \%)$ and 6 -OHDA/Veh-treated rats $(273 \pm$ $27 \%$ ) (Figure $3 \mathrm{~A}$ ). No significant difference was found between 6-OHDA/Veh and 6-OHDA/CAb groups $(\mathrm{P}=$ 0.2519) (Figure 3A). Furthermore, we analysed the quantification of microglia in different stages. Four cellular patterns (Figure 1, 2, 3, 4) were defined according to Kreutzberg's classification [46]. We observed that stage 4 cells constituted over $85 \%$ of the microglia population in the 6-OHDA/BAb-treated group, while less than 10\% of them were found in the other two groups (Figure 3B). The majority of cells presenting in the core lesion of the $\mathrm{SN}$ in the other two groups were stage 3 cells or stage 2 cells. In the 6-OHDA/Veh group, stage 3 cells constituted about $34 \%$ of the population, while $39 \%$ of population turned out to be stage 2 cells. In the 6OHDA/CAb group, 33\% of population were stage 3 cells, while $38 \%$ were stage 2 cells. Statistically significant differences were found between the 6-OHDA/BAbtreated group and the two control groups $(\mathrm{P}<0.01)$, but no difference was found between the two control groups. We also investigated the expression of MHC II, a marker for activated microglia, which is practically undetectable in resting microglia. MHC II-ir cells showed similar morphology to that of stage 4 microglia. MHC II-ir microglia were found scattered throughout the $\mathrm{SN}$ in the 6-OHDA/Veh and 6-OHDA/CAb groups (Figure $3 \mathrm{M}-\mathrm{N}$ ), while mainly stage 4 MHC II-ir microglia were visualized in the core lesion of SN from the 6OHDA/BAb treated group (Figure 3L,O). The number of stage 4 MHC II-ir microglia was dramatically increased in 6-OHDA/BAb-treated rats compared with the two control groups $(\mathrm{n}=5, \mathrm{P}<0.001)$ (Figure $3 C$ ). No difference was detected between the two control groups.

Taken together, these data suggest that BAb administration shifts stage 2 or stage 3 microglia to stage 4 in $\mathrm{SN}$. These results also show a distinct population of activated microglia (MHC II-ir), which correlates with levels of neurodegeneration and motor deficit in the 6OHDA/BAb group.

\section{BAb treatment increases 6-OHDA-induced} proinflammatory factors production in $\mathrm{SN}$

To further confirm a relationship between CD200CD200R signalling and neuroinflammation in PD, we assayed several molecules that would be secreted by activated microglia in the proinflammatory stage [10,55-59]. We detected the expression profile of two most-important cytokines, TNF- $\alpha$ and IL-6, in SN of rats from each group at 21 days post-6-OHDA-injection. This is the time point at which dopaminergic neurodegeneration, rotational behaviour and microglial activation were investigated. Interestingly, we found significant increases in the induction of TNF- $\alpha$ and IL- 6 expression in rats treated with 6-OHDA/BAb in comparison with the other treatments (6-OHDA/CAb, 6OHDA/Veh) (Figure 4, $\mathrm{P}<0.001$ ). No difference was noted between the two control groups (Figure 4). Thus we speculate that these two cytokines, TNF- $\alpha$ and IL-6, might be involved in the exacerbating effects observed in the 6-OHDA/BAb-treated animals.

\section{Discussion}

We sought in vivo evidence for a role for CD200CD200R dysfunction in the etiopathogenesis of PD. Microglia, which are not only the resident innate immune cells in the CNS $[23,46]$ but also the predominant cells that express CD200R in CNS [60], play a critical role in maintaining a homeostatic milieu for most vulnerable dopaminergic neurons. CD200-CD200R signalling is considered to be a brake on innate immunity [61]. Breaking the interaction between CD200 and CD200R will cause abnormal activation of microglia in brain.

Normal CD200-CD200R signalling maintains microglia in a quiescent state. Hoek et al. [30] first reported that disruption of CD200-CD200R interaction in the nervous system can cause EAE, which is related to abnormal activation of microglia. Recently, several studies have shown links between CD200/CD200R signalling and PD, Alzheimer's disease (AD) and prion diseases. Protein and mRNA levels of CD200 and CD200R are decreased in hippocampus and inferior 

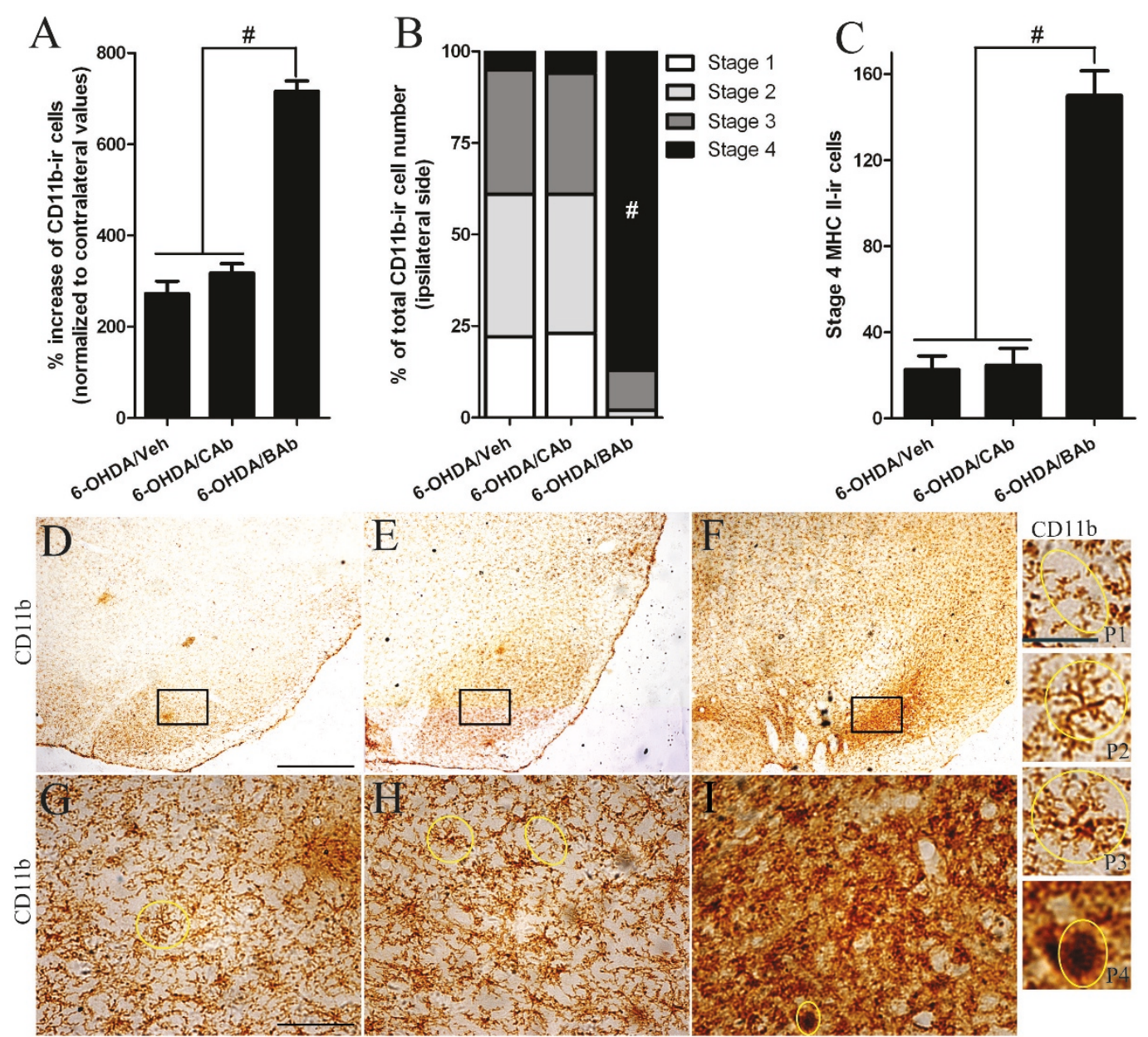

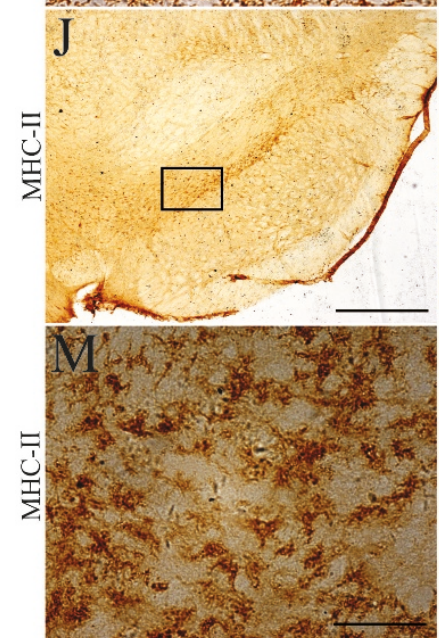

6-OHDA/Veh
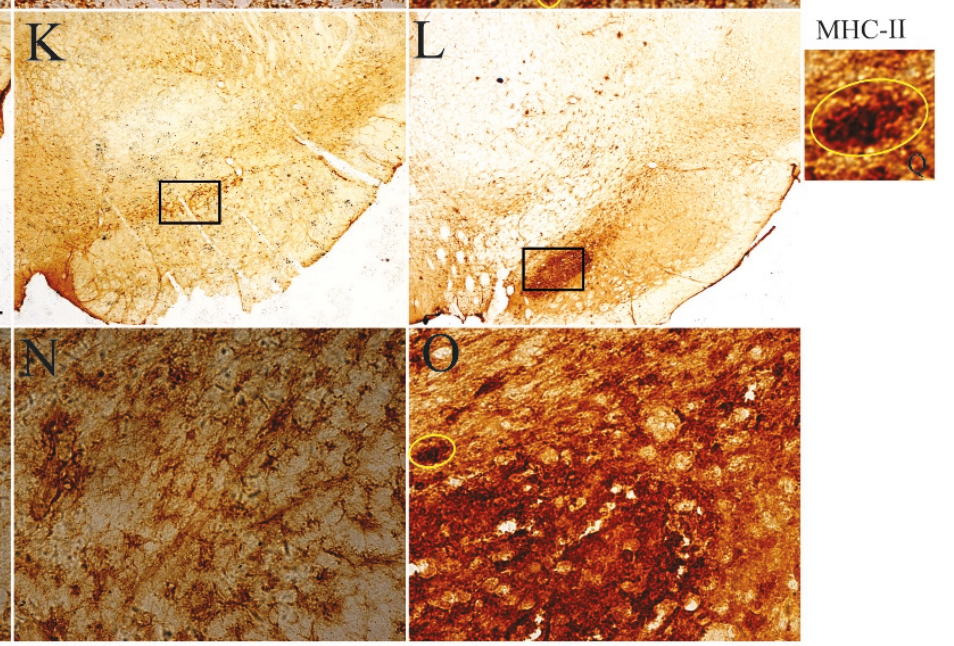

6-OHDA/CAb

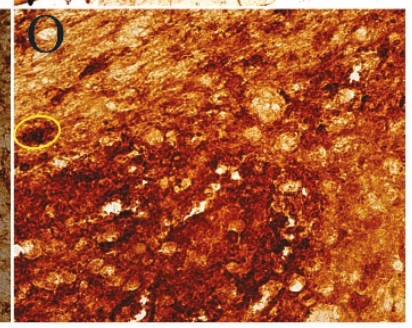

6-OHDA/BAb

Figure 3 Effects of BAb on microglial morphology and cell number in SN. Representative sections of SN in different groups were immunostained with antibodies against CD11b (a microglia marker) (D-I) and MHC II (a marker for activated microglia) (J-O) 21 days after 6OHDA-injection. G-I and M-O are higher magnifications of the fields outlined by rectangles in D-F and J-L respectively. Scale bar: $500 \mu \mathrm{m}$ in D-F and J-L; scale bar: $50 \mu \mathrm{m}$ in G-I and M-O. Representative microglia in different stages (stage1-4) of CD11b immunostaining are shown in yellow circles (stage1: P1; stage2: P2; stage3: P3; stage4: P4), and a representative of stage 4 MHC II-ir microglia is shown in panel Q. Scale bar:10 $\mu \mathrm{m}$ in P1-P4 and Q. Microglia cell numbers and morphology were stereologically analyzed in each group. (A) Data represents average increase of CD11b-ir microglia cell number in ipsilateral SN as compared to contralateral SN $(n=5) \pm$ S.E.M. \#:P $<0.001$. (B) Stereological quantification of each stage of CD11b-ir microglia is depicted as the average percentage distribution per group. \# $\mathrm{p}<0.001$ compared to every other group. (C) Stereological quantification of stage $4 \mathrm{MHC}$ II-ir cells throughout the SN from different experimental groups is shown in bar graph; $\mathrm{n}=5$, value $=$ mean \pm S.E.M. \#: $P<0.001$ significant difference compared to every other group. 


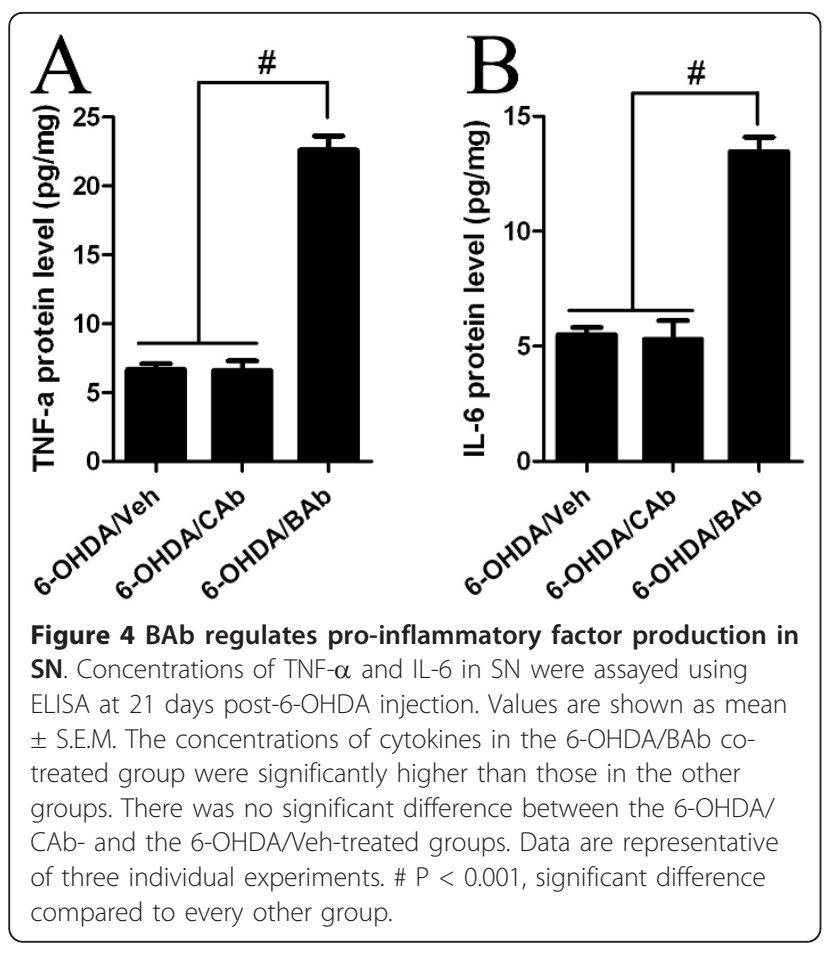

temporal gyrus of AD patients [36], suggesting that deficiency of the CD200-CD200R signalling may play an important role in the progress of AD [36]. Costello et al. [62] observed an exaggeration of proinflammatory cytokine production, including IL-1 $\beta$, IL- 6 and TNF- $\alpha$, produced by $C D 200^{-/-}$glia And these up-regulated cytokines correlated with significantly reduced longterm potentiation (LTP) at CA1 synapses of hippocampal slices from CD200/- mice [62]. These findings indicated that loss of CD200-CD200R interaction might impair synaptic function in hippocampus and play an important role in dementia. A deficit of CD200-CD200R has also been found in PD patients. Luo et al. [40] examined CD200R expression and regulation in monocyte-derived macrophages (MDMs), the peripheral counterpart of microglia, in PD patients and in old and young healthy controls. They found that basal CD200R expression is similar in MDMs from young control, old control and PD patients; however, expression of CD200R in MDMs induced by various stimuli is impaired in the older groups, especially in PD patients, implying an intrinsic abnormality of CD200-CD200R signalling in PD brain. Interestingly, CD200R expressed in human beings and rats functions only as an inhibitory signal [60]. However there are two different CD200Rs in mice $[54,60,63,64]$; an inhibitory receptor CD200R1 [48,65-68] and an activating receptor CD200R2-4 [69]. There is no report about the expression levels of CD200R or CD200 in patients with prion disease, but activated microglia are thought to be related to up- regulation of CD200R4 in a mouse model of prion disease [70]. All of these findings suggest that CD200CD200R signalling plays an important role in the pathogenesis of neurological disorders, including PD.

Previously, we always used $32 \mu$ g of 6-OHDA to yield an animal model of PD $[43,52]$. This amount would result in the demise of almost all dopaminergic neurons in the $\mathrm{SN}(>95 \%)$ and in the ventral tegmental area (VTA) $(>80 \%)$ at 3 weeks post-lesion $[43,52]$. To investigate whether abnormal CD200-CD200R signalling could exacerbate microglial activation and dopaminergic neurodegneration in the 6-OHDA-induced rat PD model, we needed to find a proper dose of 6-OHDA that would produce only a limited loss of $\mathrm{TH}$-ir neurons on the ipsilateral side of the SN. Therefore, we injected different amounts $(32 \mu \mathrm{g}, 24 \mu \mathrm{g}, 16 \mu \mathrm{g}, 8 \mu \mathrm{g})$ of 6 -OHDA into MFB and found that $16 \mu \mathrm{g}$ of 6 -OHDA was able to induce moderate but not overt dopaminergic neurodegeneration in SN (data not shown). This is the sub-toxic dose of 6-OHDA that is similar to that used by Saucer $\mathrm{H}$ et al. [71], Depino AM et al. [12] and Roedter A et al. [72]. In these studies, $20 \mu \mathrm{g} 6$-OHDA in the striatum provoked a moderate and progressive loss of dopaminergic cells in the ipsilateral SN at 3 weeks post -lesion. The typical phenotype and corresponding neurodegeneration, as well as augmented microglial activation, observed in 6-OHDA/BAb-treated rats suggests that abnormal CD200-CD200R signalling exacerbates microglial activation and plays an important role in progression of the disease. It is believed that multiple factors are involved in the development of PD. Our present study in a PD rat model and our previous study in PD patients indicate that both intrinsic abnormal CD200CD200R signalling and environmental neurotoxins participate in the pathogenesis of PD.

According to previous studies, the bolus administration of any substance into cerebrum may cause mechanical damage to neurons $[73,74]$ and subsequent adjacent activation of microglia [74-79]. This makes it difficult to distinguish activation of microglia caused by injection from that caused by changes in CD200-CD200R signalling. Beside this, the small volume of the $\mathrm{SN}$ makes it hard to inject any reagent precisely into the $\mathrm{SN}[80,81]$. Finding an ideal alternative antibody injection site would help to elucidate the role of CD200-CD200R signalling in the pathogenesis of PD. Phaseolus vulgarisleucoagglutinin and biocytin, injected into striatum, can later be found in substantia nigra pars reticulate (SNpr) and substantia nigra pars compacta $(\mathrm{SNpc})$ in squirrel monkeys [82]. In addition, Mufson et al [83] have shown that intrastriatral infusion of the tracer fluorogold results in transport into the SNpc. The above evidence indicates that antibody injected into striatum may spread into the $\mathrm{SN}$, causing abnormal activation of 
microglia and damage to dopaminergic neurons. Histological and immunological examinations in rats confirmed our speculation. Furthermore, the reduced levels of DA and its metabolites caused by injection of BAb in striatum demonstrates impairment of dopaminergic neurons in $\mathrm{SN}$.

The results of this study provide in vivo evidence that impairment of CD200-CD200R signalling might play an important role in the pathogenesis of PD. However, our study lacked a time course of microglial activation and neuroinflammation. Therefore, further study is required to fully elucidate the mechanism involved in microglial activation and subsequent neurodegeneration.

\section{Conclusions}

Taking all of these results together, this study shows that disruption of CD200-CD200R signalling might play a role in the pathogenesis of PD. The role of CD200CD200R signalling in the pathogenesis of PD makes it a potential therapeutic target for PD therapy. Therapeutic agents that can efficiently inhibit microglial activation through regulation of CD200-CD200R signalling may become a novel approach to the clinical treatment of PD.

\section{Acknowledgements}

We thank Dr. Hai-Yan Qiu for her technical advice on crytostat section preparation, and Mrs. Yu-Ying Chen for advice on immunohistochemical skills. This work was funded by the National Program of Basic Research (2007CB947900, 2010CB945200, 2011CB504104) of China, the National Natural Science Fund $(30772280,30700888,30770732,30872729$, 30971031), Key Discipline Program of Shanghai Municipality (\$30202), Shanghai Key Project of Basic Science Research (10411954500), and Program for Outstanding Medical Academic Leader of Shanghai $(\sqcup$ 06003).

\section{Author details}

${ }^{1}$ Department of Neurology \& Institute of Neurology, Ruijin Hospital, Shanghai Jiao Tong University School of Medicine, 197 Ruijin Er Road, Shanghai 200025, P. R. China. 'Laboratory of Neurodegenerative Diseases \& key Laboratory of Stem Cell Biology, Institute of Health Science, Shanghai Institutes of Biological Sciences (SIBS), Chinese Academy of Science (CAS) \& Shanghai Jiao Tong University School of medicine, 225 South Chong Qing Road, Shanghai 200025, P. R. China.

\section{Authors' contributions}

SZ, XJW, JQD, SDC designed research. SZ, LPT, JP, GQL, YJZ performed research. SZ wrote paper. All authors read and approved the final manuscript.

\section{Competing interests}

The authors declare that they have no competing interests.

Received: 28 May 2011 Accepted: 6 November 2011

Published: 6 November 2011

\section{References}

1. Braak H, Del Tredici K, Rub U, de Vos RA, Jansen Steur EN, Braak E: Staging of brain pathology related to sporadic Parkinson's disease. Neurobiol Aging 2003, 24:197-211.

2. Gallagher DA, Schapira AH: Etiopathogenesis and treatment of Parkinson's disease. Curr Top Med Chem 2009, 9:860-868.
3. Savitt JM, Dawson VL, Dawson TM: Diagnosis and treatment of Parkinson disease: molecules to medicine. J Clin Invest 2006, 116:1744-1754.

4. Eriksen $J$ L, Wszolek Z, Petrucelli L: Molecular pathogenesis of Parkinson disease. Arch Neurol 2005, 62:353-357.

5. Gerhard A, Pavese N, Hotton G, Turkheimer F, Es M, Hammers A, Eggert K, Oertel W, Banati RB, Brooks DJ: In vivo imaging of microglial activation with [11C](R)-PK11195 PET in idiopathic Parkinson's disease. Neurobiol Dis 2006, 21:404-412.

6. Hunot S, Dugas N, Faucheux B, Hartmann A, Tardieu M, Debre P, Agid Y, Dugas B, Hirsch EC: FcepsilonRII/CD23 is expressed in Parkinson's disease and induces, in vitro, production of nitric oxide and tumor necrosis factor-alpha in glial cells. J Neurosci 1999, 19:3440-3447.

7. McGeer PL, Itagaki S, Boyes BE, McGeer EG: Reactive microglia are positive for HLA-DR in the substantia nigra of Parkinson's and Alzheimer's disease brains. Neurology 1988, 38:1285-1291.

8. Ouchi Y, Yoshikawa E, Sekine Y, Futatsubashi M, Kanno T, Ogusu T, Torizuka T: Microglial activation and dopamine terminal loss in early Parkinson's disease. Ann Neurol 2005, 57:168-175.

9. Mirza B, Hadberg H, Thomsen P, Moos T: The absence of reactive astrocytosis is indicative of a unique inflammatory process in Parkinson's disease. Neuroscience 2000, 95:425-432.

10. Vila M, Jackson-Lewis V, Guegan C, Wu DC, Teismann P, Choi DK, Tieu K, Przedborski S: The role of glial cells in Parkinson's disease. Curr Opin Neurol 2001, 14:483-489.

11. Gao HM, Jiang J, Wilson B, Zhang W, Hong JS, Liu B: Microglial activationmediated delayed and progressive degeneration of rat nigral dopaminergic neurons: relevance to Parkinson's disease. J Neurochem 2002, 81:1285-1297.

12. Depino AM, Earl C, Kaczmarczyk E, Ferrari C, Besedovsky H, del Rey A, Pitossi FJ, Oertel WH: Microglial activation with atypical proinflammatory cytokine expression in a rat model of Parkinson's disease. Eur J Neurosci 2003, 18:2731-2742.

13. Ferrari CC, Depino AM, Prada F, Muraro N, Campbell S, Podhajcer O, Perry VH, Anthony DC, Pitossi FJ: Reversible demyelination, blood-brain barrier breakdown, and pronounced neutrophil recruitment induced by chronic IL-1 expression in the brain. Am J Pathol 2004, 165:1827-1837.

14. Mogi M, Harada M, Riederer $P$, Narabayashi $H$, Fujita $K$, Nagatsu T: Tumor necrosis factor-alpha (TNF-alpha) increases both in the brain and in the cerebrospinal fluid from parkinsonian patients. Neurosci Lett 1994, 165:208-210.

15. Boka G, Anglade P, Wallach D, Javoy-Agid F, Agid Y, Hirsch EC: Immunocytochemical analysis of tumor necrosis factor and its receptors in Parkinson's disease. Neurosci Lett 1994, 172:151-154.

16. Mogi $M$, Harada $M$, Kondo $T$, Riederer $P$, Inagaki $H$, Minami $M$, Nagatsu $T$ : Interleukin-1 beta, interleukin-6, epidermal growth factor and transforming growth factor-alpha are elevated in the brain from parkinsonian patients. Neurosci Lett 1994, 180:147-150.

17. Brodacki B, Staszewski J, Toczylowska B, Kozlowska E, Drela N, Chalimoniuk M, Stepien A: Serum interleukin (IL-2, IL-10, IL-6, IL-4), TNFalpha, and INFgamma concentrations are elevated in patients with atypical and idiopathic parkinsonism. Neurosci Lett 2008, 441:158-162.

18. Nagatsu T, Sawada M: Biochemistry of postmortem brains in Parkinson's disease: historical overview and future prospects. J Neural Transm Suppl 2007, 113-120.

19. Hartmann A, Troadec JD, Hunot S, Kikly K, Faucheux BA, Mouatt-Prigent A, Ruberg M, Agid Y, Hirsch EC: Caspase-8 is an effector in apoptotic death of dopaminergic neurons in Parkinson's disease, but pathway inhibition results in neuronal necrosis. J Neurosci 2001, 21:2247-2255.

20. Ferrer I, Blanco R, Carmona M, Puig B, Barrachina M, Gomez C, Ambrosio S: Active, phosphorylation-dependent mitogen-activated protein kinase (MAPK/ERK), stress-activated protein kinase/c-Jun N-terminal kinase (SAPK/JNK), and p38 kinase expression in Parkinson's disease and Dementia with Lewy bodies. J Neural Transm 2001, 108:1383-1396.

21. Mogi M, Togari A, Kondo T, Mizuno Y, Komure O, Kuno S, Ichinose H, Nagatsu T: Caspase activities and tumor necrosis factor receptor R1 (p55) level are elevated in the substantia nigra from parkinsonian brain. $J$ Neural Transm 2000, 107:335-341.

22. Iravani MM, Kashefi K, Mander P, Rose S, Jenner P: Involvement of inducible nitric oxide synthase in inflammation-induced dopaminergic neurodegeneration. Neuroscience 2002, 110:49-58. 
23. Kitamura $\mathrm{T}$ : The origin of brain macrophages-some considerations on the microglia theory of Del Rio-Hortega. Acta Pathol Jpn 1973, 23:11-26.

24. Gorczynski R, Chen Z, Kai Y, Lee L, Wong S, Marsden PA: CD200 is a ligand for all members of the CD200R family of immunoregulatory molecules. J Immunol 2004, 172:7744-7749.

25. Webb M, Barclay AN: Localisation of the MRC OX-2 glycoprotein on the surfaces of neurones. J Neurochem 1984, 43:1061-1067.

26. Vieites JM, de la Torre R, Ortega MA, Montero T, Peco JM, Sanchez-Pozo A, Gil A, Suarez A: Characterization of human cd200 glycoprotein receptor gene located on chromosome 3q12-13. Gene 2003, 311:99-104.

27. Wright GJ, Jones M, Puklavec MJ, Brown MH, Barclay AN: The unusual distribution of the neuronal/lymphoid cell surface CD200 (OX2) glycoprotein is conserved in humans. Immunology 2001, 102:173-179.

28. Barclay AN: Different reticular elements in rat lymphoid tissue identified by localization of la, Thy-1 and MRC OX 2 antigens. Immunology 1981, 44:727-736.

29. Barclay AN, Ward HA: Purification and chemical characterisation of membrane glycoproteins from rat thymocytes and brain, recognised by monoclonal antibody MRC OX 2. Eur J Biochem 1982, 129:447-458.

30. Hoek RM, Ruuls SR, Murphy CA, Wright GJ, Goddard R, Zurawski SM, Blom B, Homola ME, Streit WJ, Brown MH, et al: Down-regulation of the macrophage lineage through interaction with OX2 (CD200). Science 2000, 290:1768-1771.

31. Deckert M, Sedgwick JD, Fischer E, Schluter D: Regulation of microglial cell responses in murine Toxoplasma encephalitis by CD200/CD200 receptor interaction. Acta Neuropathol 2006, 111:548-558.

32. Wright GJ, Puklavec MJ, Willis AC, Hoek RM, Sedgwick JD, Brown MH, Barclay AN: Lymphoid/neuronal cell surface OX2 glycoprotein recognizes a novel receptor on macrophages implicated in the control of their function. Immunity 2000, 13:233-242.

33. Banerjee D, Dick AD: Blocking CD200-CD200 receptor axis augments NOS-2 expression and aggravates experimental autoimmune uveoretinitis in Lewis rats. Ocul Immunol Inflamm 2004, 12:115-125.

34. Taylor N, McConachie K, Calder C, Dawson R, Dick A, Sedgwick JD, Liversidge J: Enhanced tolerance to autoimmune uveitis in CD200deficient mice correlates with a pronounced Th2 switch in response to antigen challenge. J Immunol 2005, 174:143-154.

35. Copland DA, Calder CJ, Raveney BJ, Nicholson LB, Phillips J, Cherwinski H, Jenmalm M, Sedgwick JD, Dick AD: Monoclonal antibody-mediated CD200 receptor signaling suppresses macrophage activation and tissue damage in experimental autoimmune uveoretinitis. Am J Pathol 2007 171:580-588.

36. Walker DG, Dalsing-Hernandez JE, Campbell NA, Lue LF: Decreased expression of CD200 and CD200 receptor in Alzheimer's disease: a potential mechanism leading to chronic inflammation. Exp Neurol 2009, 215:5-19.

37. Koning N, Bo L, Hoek RM, Huitinga I: Downregulation of macrophage inhibitory molecules in multiple sclerosis lesions. Ann Neurol 2007 62:504-514

38. Wang XJ, Ye M, Zhang YH, Chen SD: CD200-CD200R regulation of microglia activation in the pathogenesis of Parkinson's disease. $J$ Neuroimmune Pharmacol 2007, 2:259-264.

39. Koning N, Uitdehaag BM, Huitinga I, Hoek RM: Restoring immune suppression in the multiple sclerosis brain. Prog Neurobiol 2009, 89:359-368.

40. Luo XG, Zhang JJ, Zhang CD, Liu R, Zheng L, Wang XJ, Chen SD, Ding JQ: Altered regulation of CD200 receptor in monocyte-derived macrophages from individuals with Parkinson's disease. Neurochem Res 35:540-547.

41. Wang XJ, Zhang S, Yan ZQ, Zhao YX, Zhou HY, Wang Y, Lu GQ, Zhang JD: Impaired CD200-CD200R-mediated microglia silencing enhances midbrain dopaminergic neurodegeneration: Roles of aging, superoxide, NADPH oxidase, and p38 MAPK. Free Radic Biol Med 2011, 50:1094-1106.

42. West MJ, Slomianka L, Gundersen HJ: Unbiased stereological estimation of the total number of neurons in thesubdivisions of the rat hippocampus using the optical fractionator. Anat Rec 1991, 231:482-497.

43. Pan J, Wang G, Yang HQ, Hong Z, Xiao Q, Ren RJ, Zhou HY, Bai L, Chen SD: K252a prevents nigral dopaminergic cell death induced by 6 hydroxydopamine through inhibition of both mixed-lineage kinase 3/cJun NH2-terminal kinase 3 (JNK3) and apoptosis-inducing kinase 1/JNK3 signaling pathways. Mol Pharmacol 2007, 72:1607-1618.
44. German DC, Manaye KF: Midbrain dopaminergic neurons (nuclei A8, A9, and A10): three-dimensional reconstruction in the rat. J Comp Neurol 1993, 331:297-309.

45. Lowry OH, Rosebrough NJ, Farr AL, Randall RJ: Protein measurement with the Folin phenol reagent. J Biol Chem 1951, 193:265-275.

46. Kreutzberg GW: Microglia: a sensor for pathological events in the CNS. Trends Neurosci 1996, 19:312-318.

47. Ungerstedt $U$, Arbuthnott GW: Quantitative recording of rotational behavior in rats after 6-hydroxy-dopamine lesions of the nigrostriatal dopamine system. Brain Res 1970, 24:485-493.

48. Gorczynski R, Khatri I, Lee L, Boudakov I: An interaction between CD200 and monoclonal antibody agonists to CD200R2 in development of dendritic cells that preferentially induce populations of CD4+CD25+ T regulatory cells. J Immunol 2008, 180:5946-5955.

49. Gorczynski RM: Transplant tolerance modifying antibody to CD200 receptor, but not CD200, alters cytokine production profile from stimulated macrophages. Eur J Immunol 2001, 31:2331-2337.

50. Gorczynski RM, Chen Z, Lee L, Yu K, Hu J: Anti-CD200R ameliorates collagen-induced arthritis in mice. Clin Immunol 2002, 104:256-264.

51. Gorczynski RM, Yu K, Clark D: Receptor engagement on cells expressing a ligand for the tolerance-inducing molecule OX2 induces an immunoregulatory population that inhibits alloreactivity in vitro and in vivo. J Immunol 2000, 165:4854-4860.

52. Pan J, Zhao YX, Wang ZQ, Jin L, Sun ZK, Chen SD: Expression of Fas L and its interaction with Fas are mediated by c-Jun $\mathrm{N}$-terminal kinase (JNK) pathway in 6-OHDA-induced rat model of Parkinson disease. Neurosci Lett 2007, 428:82-87.

53. Gorczynski RM: CD200 and its receptors as targets for immunoregulation. Curr Opin Investig Drugs 2005, 6:483-488.

54. Gorczynski RM, Chen Z, Clark DA, Kai Y, Lee L, Nachman J, Wong S, Marsden P: Structural and functional heterogeneity in the CD200R family of immunoregulatory molecules and their expression at the fetomaternal interface. Am J Reprod Immunol 2004, 52:147-163.

55. Nagatsu T, Mogi M, Ichinose $H$, Togari A: Changes in cytokines and neurotrophins in Parkinson's disease. J Neural Transm Supp/ 2000, 277-290.

56. Hirsch EC, Hunot S: Neuroinflammation in Parkinson's disease: a target for neuroprotection? Lancet Neurol 2009, 8:382-397.

57. Lucas SM, Rothwell NJ, Gibson RM: The role of inflammation in CNS injury and disease. Br J Pharmacol 2006, 147(Suppl 1):S232-240.

58. McGeer PL, McGeer EG: Inflammation and neurodegeneration in Parkinson's disease. Parkinsonism Relat Disord 2004, 10(Suppl 1):S3-7.

59. Streit WJ: Microglial response to brain injury: a brief synopsis. Toxicol Pathol 2000, 28:28-30.

60. Wright GJ, Cherwinski H, Foster-Cuevas M, Brooke G, Puklavec MJ, Bigler M, Song Y, Jenmalm M, Gorman D, McClanahan T, et al: Characterization of the CD200 receptor family in mice and humans and their interactions with CD200. J Immunol 2003, 171:3034-3046.

61. Nathan C, Muller WA: Putting the brakes on innate immunity: a regulatory role for CD200? Nat Immunol 2001, 2:17-19.

62. Costello DA, Lyons A, Browne T, Denieffe S, Cox FF, Lynch MA: Long-term potentiation is impaired in CD200-deficient mice: a role for Toll-like receptor activation. J Biol Chem 2011.

63. Akkaya M, Barclay AN: Heterogeneity in the CD200R paired receptor family. Immunogenetics 2010, 62:15-22.

64. Hatherley D, Cherwinski HM, Moshref M, Barclay AN: Recombinant CD200 protein does not bind activating proteins closely related to CD200 receptor. J Immunol 2005, 175:2469-2474.

65. Boudakov I, Liu J, Fan N, Gulay P, Wong K, Gorczynski RM: Mice lacking CD200R1 show absence of suppression of lipopolysaccharide-induced tumor necrosis factor-alpha and mixed leukocyte culture responses by CD200. Transplantation 2007, 84:251-257.

66. Simelyte E, Alzabin S, Boudakov I, Williams R: CD200R1 regulates the severity of arthritis but has minimal impact on the adaptive immune response. Clin Exp Immunol 2010, 162:163-168.

67. Liu Y, Bando Y, Vargas-Lowy D, Elyaman W, Khoury SJ, Huang T, Reif K, Chitnis T: CD200R1 agonist attenuates mechanisms of chronic disease in a murine model of multiple sclerosis. J Neurosci 2010, 30:2025-2038.

68. Masocha W: CD200 receptors are differentially expressed and modulated by minocycline in the brain during Trypanosoma brucei infection. $J$ Neuroimmunol 2010, 226:59-65. 
69. Kojima T, Obata K, Mukai K, Sato S, Takai T, Minegishi Y, Karasuyama H: Mast cells and basophils are selectively activated in vitro and in vivo through CD200R3 in an IgE-independent manner. J Immunol 2007, 179:7093-7100.

70. Lunnon K, Teeling JL, Tutt AL, Cragg MS, Glennie MJ, Perry VH: Systemic inflammation modulates $\mathrm{Fc}$ receptor expression on microglia during chronic neurodegeneration. J Immunol 2011, 186:7215-7224.

71. Sauer $\mathrm{H}$, Oertel WH: Progressive degeneration of nigrostriatal dopamine neurons following intrastriatal terminal lesions with 6-hydroxydopamine: a combined retrograde tracing and immunocytochemical study in the rat. Neuroscience 1994, 59:401-415.

72. Roedter A, Winkler C, Samii M, Walter GF, Brandis A, Nikkhah G: Comparison of unilateral and bilateral intrastriatal 6-hydroxydopamineinduced axon terminal lesions: evidence for interhemispheric functional coupling of the two nigrostriatal pathways. J Comp Neurol 2001, 432:217-229.

73. Akerman S, Goadsby PJ: Topiramate inhibits cortical spreading depression in rat and cat: impact in migraine aura. Neuroreport 2005, 16:1383-1387.

74. Allan SM, Parker LC, Collins B, Davies R, Luheshi GN, Rothwell NJ: Cortical cell death induced by IL-1 is mediated via actions in the hypothalamus of the rat. Proc Natl Acad Sci USA 2000, 97:5580-5585.

75. McCluskey L, Campbell S, Anthony D, Allan SM: Inflammatory responses in the rat brain in response to different methods of intra-cerebral administration. J Neuroimmunol 2008, 194:27-33.

76. Amat JA, Ishiguro H, Nakamura K, Norton WT: Phenotypic diversity and kinetics of proliferating microglia and astrocytes following cortical stab wounds. Glia 1996, 16:368-382

77. Kyrkanides S, O'Banion MK, Whiteley PE, Daeschner JC, Olschowka JA: Enhanced glial activation and expression of specific CNS inflammationrelated molecules in aged versus young rats following cortical stab injury. J Neuroimmunol 2001, 119:269-277.

78. Shibayama M, Kuchiwaki H, Inao S, Yoshida K, Ito M: Intercellular adhesion molecule-1 expression on glia following brain injury: participation of interleukin-1 beta. J Neurotrauma 1996, 13:801-808.

79. Ghirnikar RS, Lee YL, Eng LF: Inflammation in traumatic brain injury: role of cytokines and chemokines. Neurochem Res 1998, 23:329-340.

80. Carman LS, Gage FH, Shults CW: Partial lesion of the substantia nigra: relation between extent of lesion and rotational behavior. Brain Res 1991, 553:275-283

81. Deumens R, Blokland A, Prickaerts J: Modeling Parkinson's disease in rats: an evaluation of 6-OHDA lesions of the nigrostriatal pathway. Exp Neurol 2002, 175:303-317.

82. Parent A, Hazrati LN: Multiple striatal representation in primate substantia nigra. J Comp Neurol 1994, 344:305-320.

83. Mufson EJ, Kroin JS, Sobreviela T, Burke MA, Kordower JH, Penn RD, Miller JA: Intrastriatal infusions of brain-derived neurotrophic factor: retrograde transport and colocalization with dopamine containing substantia nigra neurons in rat. Exp Neurol 1994, 129:15-26.

doi:10.1186/1742-2094-8-154

Cite this article as: Zhang et al:: CD200-CD200R dysfunction exacerbates microglial activation and dopaminergic neurodegeneration in a rat model of Parkinson's disease. Journal of Neuroinflammation 2011 8:154.

\section{Submit your next manuscript to BioMed Central and take full advantage of:}

- Convenient online submission

- Thorough peer review

- No space constraints or color figure charges

- Immediate publication on acceptance

- Inclusion in PubMed, CAS, Scopus and Google Scholar

- Research which is freely available for redistribution 